\title{
Basit ve anevrizmal kemik kistleri
}

\section{Simple and aneurysmal bone cysts}

\author{
Serdar Özbarlas
}

Özel Ortopedia Hastanesi, Adana

\begin{abstract}
Basit kemik kisti, içinde seröz bir mayi olan kemikte metafize yerleşen, puberteye kadar büyüyen ve etiyopatogenezi bilinmeyen atrofik, dejeneratif bir kemik lezyonudur. Kemiğin psödotümörleri sınıflaması içinde yer alır. Histiyositik fibroma ve ekzositozdan sonra en sık görülen kemik tümörüdür. En sık 5-15 yaşlar arasında olmak üzere, erkeklerde iki kat daha fazla görülür; en çok proksimal humerus ve daha sonra proksimal femur, sevdiği yerleşim bölgeleridir. Ağrısız bir lezyon olduğu için ancak patolojik kırık veya insidental olarak tanı alır. Tedavide küretaj ve greftleme konvansiyonel yöntemdir. Ancak Scaglietti ve arkadaşları tarafından popülarize edilen steroid enjeksiyonu tekniği[1] başta olmak üzere, otolog kemik iliği enjeksiyonu, multipl drilleme, intramedüller çivileme gibi değişik yöntemler geliştirilmiştir.
\end{abstract}

Anevrizmal kemik kisti kemiğin psödotümörlerinden olup, ağrı ve şişlikle karakterize ve ekspansil yapıda kemik lezyonudur. Yapısal olarak hemorajik ve hiperplastik natürde olup etiyopatolojisi bilinmemektedir. Kadınlarda biraz daha fazla olmak üzere, 10-20 yaşlar arasında sık görülür. Anevrizmal kemik kisti tüm kemik tümörlerinin \%1-2'sini oluşturur. ${ }^{[2]}$ Vücüdun tüm kemiklerinde görülebilmekle birlikte, alt ekstremite uzun kemikleri, vertebra ve üst ekstremite uzun kemikleri sık görüldüğü yerlerdir. Herhangi bir kemikte görülebilir ama en yaygın olarak alt ekstremite uzun kemikleri, omurga ve üst ekstremite uzun kemiklerinde rastlanır. Giant cell, brown tümör, kondroblastom, osteoblastom gibi tümörlerin alanlarında gözlenebildiği gibi, daha önce tespit edilmiş başka bir tümörün hemorajik transformasyonu da olarak da ortaya çıkabilir. Genellikle progresif lezyonlardır ama nadiren yavaş ilerleyen ve tedavi edilmeyip yavaş ossifiye olan olgular görülebilmektedir. Anevrizmal kemik kistinin bu matürasyonu radyoterapi ve selektif arteriyel embolizasyonla sağlanabilmektedir. Tedavide küretaj ve greftlemeye ameliyat sırasında lokal adjuvant olarak fenol, sıvı nitrojen ve kemik çimentosu eklemek gerekir. Rekürrens \%10-15 arasında bildirilmektedir.

Anahtar sözcükler: kemik kistleri; benign tümörler; anevrizmal kemik kistleri
Simple bone cyst is a bone lesion having a serous content localized in the metaphysis developing during the growth age. Its nature is atrophic, degenerative and its etiopathogenesis is unknown. It is classified in the pseudotumors of the bone with frequent occurence after histiocytic fibroma and exostosis. Incidence is greater in male sex at a ratio of 2:1 and most of the patients are 5 to 15 years of age; more than half of the cases are localized in the proximal humerus, less frequently in proximal femur and other locations. It is a painless lesion and therefore it is diagnosed secondary to a pathologic fracture or incidentally. Simple bone cyst is conventionally treated by curettage and bone grafting. But, primarily with the steroid injection technique popularized by Scaglietti et al., , ${ }^{[1]}$ different types of surgery were described and advocated such as autologous bone marrow injection, multiple drilling, intramedullary nailing.

Aneurysmal bone cyst is an expansive pseudotumoral lesion of bone clinically characterised by pain and swelling. Structurally it is hyperemic and its genesis is unknown. It is most frequently observed from 10 to 20 years of age and there is a slight predilection for the female sex. Aneurysmal bone cyst constitutes $1-2 \%$ of all bone tumours. ${ }^{[2]}$ It may be observed in any site of the skeleton but the most common sites are long bones of the lower limb, the vertebral column and the long bones of the upper limb. It may be observed in some areas of other tumors such as giant cell, brown tumor, chondroblastoma, osteoblastoma or it may be a hemorrhagic transformation of another previously affirmed tumor. They are generally progresive lesions but we occasionally encounter cases with small growth rate that slowly ossify without any treatment. This maturation is induced by radiation or selective arterial embolization. The choise of treatment is extraperiosteal excision and curettage associated with the use of local adjuvants such as phenol, liquid nitrogen, bone cement and bone grafting. Recurrence of 10-15\% have been reported.

Key words: bone cysts; benign neoplasms; aneurysmal bone cysts

- Illetişim adresi: Prof. Dr. Serdar Özbarlas, Özel Ortopedia Hastanesi, Adana Tel: 0532 - 3518951 e-posta: serdarozbarlas@gmail.com

- Geliș tarihi: 27 Eylül 2013 Kabul tarihi: 27 Eylül 2013 


\section{BASIT KEMIK KISTi}

Basit kemik kisti (BKK) klinik, radyolojik ve histopatolojik olarak Jaffe ve Lichtenstein tarafindan 1942'de tanımlanmıştır. ${ }^{[3]}$ BKK büyümekte olan çocuklarda görülen benign lezyonlardır. Olgular büyük oranda proksimal humerusta (\%55-70) ve daha sonra femurda (\%20) görülür. Pelvis ve kalkaneus yerleşimi ile ilgili yayınlar vardır. ${ }^{[4-6]}$ Erkeklerde daha sık görülür ve tüm kemik tümörlerinde görülme sıklığı \%3 civarındadır. ${ }^{[7]}$ Epifize komşu metafiz tipik yerleşim yeridir. Her yaşta görülebilmekle birlikte en çok 5-15 yaşlar arası tanı alır. Ağrısız bir lezyon olduğu için, patolojik kırık olunca tanı alır. Kistler, patolojik kırıktan sonra, sadece immobilizasyonla \%15 oranında iyileşir. illium ve kalkaneustaki olgular erişkin dönemde insidental olarak tanı alır. Nadiren epifizi etkileyip humerus veya femurda kısalığa neden olabilir.

\section{Radyoloji}

Semptomsuz seyrettiği için çok nadiren, şans eseri erken dönemde tanı alır. Santral bir osteoliz vardır ve kortekste ekspansiyon görülür. Kistin sınırları belirgin olmakla birlikte çevresinde skleroz ya hiç yoktur ya da çok incedir. Korteks etkilenmekle birlikte devamlılığı vardır ve kırık olana kadar periost reaksiyonu yoktur. Kist kavitesi fibröz veya ince kemik septalarla bölünüp çok kamaralı hale dönüşebilir. Bazen kist duvarının inkomplet kırığı ile oluşan ince bir kemik parça kavitenin içine düşer ve basit kemik kistinin en patognomik radyolojik belirtisi olan 'fallen fragment sign' (düşmüş fragman belirtisi) oluşur. Lezyon çok nadiren epifizi geçer.

\section{Makroskopik görünüm}

Periost daima intakttır. Korteks yumurta kabuğu gibi incelmiştir, ancak devamlılığı vardır (patolojik kırık oluşmamışsa). Kavite serum benzeri bir sıvı ile doludur ama patolojik kırık oluşunca hemorajik sıvı ile karşılaşılır. Kistin iç duvarı ince yumuşak bir membran ile döşenmiştir. Bu membran çok kırılgandır ve kemikten kolayca sıyrılarak ayrılır. Eğer patolojik kırık veya geçirilmiş ameliyat varsa sarımsı kahverengi renkte, daha koyu kıvamlı bir içerik görülebilir.

\section{Histopatoloji}

Membran spesifik olmayan gevşek bir kollajenden oluşur. Bu bağ dokusunda küçük hemorajiler ve çok küçük miktarda yeni kemik trabekülleri, makrofajlar, dev hücreler ve lenfomonositer infiltrasyon görülür. $\mathrm{Bu}$, herhangi bir iskelet lezyonunun uç kısımında görülebilen reaktif ve tamir dokusudur. Kemik duvarda ise yeni kemik oluşumu ve genişlemiş, fazla vaskülarize olmayan Haversian kanallardan oluşur.

\section{Patogenez}

Basit kemik kisti, patogenesisi bilinmemekle birlikte, başlangıçta büyüme sırasında inflamasyon ve displastik süreçlerle açıklanmaya çalışılmış, travmatik nedenler suçlanmış̧, ${ }^{[3]}$ neden olarak intrakaviter osseöz basınç artışı bildirilmiştir. ${ }^{[8]}$ Komiya 1993'te kist sıvısını incelemiş; bone resorbing factor, prostoglandin, interlokin 1, polyacrylamid gel (sodyum dodesil sülfat içerir) ve polimerize sülfat düzeylerinde artış ve protein elektroforezinde, proteolitik enzimlerde artış saptamıştır. ${ }^{[9]}$ Kist sıvısındaki bu faktörlerin osteoblastik aktiviteyi arttırarak kemik rezorbsiyonundan sorumlu olabileceği ileri sürülmüştür. ${ }^{[10,11]}$

\section{Tanı}

Genellikle klinik ve radyolojik verilerle tanı konabilmektedir. Proksimal humerus, proksimal femur yerleşimi, patolojik kırık oluşana kadar ağıı olmayışı ve radyolojik görüntü ile tanı konabilir. Kaviteden bir iğneyle serohemorajik sıvı çekmek tanıyı hemen hemen kesinleştirir. Ayırıcı tanıda; radyolojik olarak anevrizmal kemik kistine benzeyebilir, ama eksentrik yerleşimi ve kortekste aşırı ekspansiyon ile farklıdır. Ancak genişleyip tüm metafizi tutanlarda ayrım zorlaşır. Erişkin dönem iyi sınırlanmış fibröz displaziler eski basit kemik kistleri ile karıştırılır.

\section{Hastalığın seyri}

Hastalık muhtemelen 10 yaş altında, metafizde santral küçük bir osteolizle başlar. Birkaç ay ile bir yıl arasında bir süre sonunda metafize yayılır. Kist aktif kaldığı sürece içi sıvı ile dolar ve metafizer trabekülleri baskı altına alarak resorbe eder. Kistin aktivitesi yavaşladığında, epifizden uzaklaşıp diafize doğru yer değiştirir. Genelde basit kemik kistleri aktif ve inaktif olarak ikiye ayrılır. Jaffe ve Lichtenstein, epifize $10 \mathrm{~mm}$ yakınlıkta olan kistlere aktif, $10 \mathrm{~mm}$ 'den uzak olanlara latent (inaktif) kist demişlerdir. ${ }^{[3]} 10-12$ yaş altındaki olgularda epifize komşu korteksi inceltmiş ve kist içi basınç $30 \mathrm{~cm}$ su basıncından fazla ise aktif kist, 10-12 yaş üstü olgularda epifizden uzak, korteks kalın, multilokuler kistler inaktif kist olarak kabul edilir. Yaş ile kistin aktivitesi arasında ilişki vardır ve genelde hastanın iskelet matürasyonu ile kistin aktivitesi durur.

\section{Tedavi}

Basit kemik kistlerinde tedavi başlangıçta küretaj ve greftlemeydi. Bu teknikle yüksek rekürrens oranları (\%30) bildirilmiştir. ${ }^{[12]}$ Scaglietti ve arkadaşları 1973'te, kist sıvısının transüdasyonundan yola çıkarak ve sinoviyal effüzyonların antiinflamatuvar tedavisindeki başarılı sonuçları gözönüne alarak; basit kemik kistlerinde perkütan metilprednizolon asetat 
enjeksiyonu ile tedaviyi gündeme getirmişlerdir. ${ }^{[1]}$ Daha sonra Yu ve arkadaşları, kist duvarının sinoviyositlere benzer tek katlı hücrelerle kaplı olduğundan yola çıkarak, sinoviyum hücre kültürlerine metilprednizolon asetat vermişler, sonuçta hücre fonksiyon ve replikasyonunda düşme kaydetmişlerdir. ${ }^{[13]}$ Capanna steroid enjeksiyonu tekniği ile nüks oranlarını \%13,5'e düşürmüşler ve nüks için risk faktörlerini; multilokülasyon, kist büyüklüğü ve hasta yaşı olarak bildirmişlerdir. ${ }^{[14]}$ Steroid enjeksiyonu, kist kavitesini serum fizyolojik ile yıkadıktan sonra 40-120 mg metilprednizolon asetat uygulayarak yapılır. İşlem iki ay arayla tekrarlanacak şekilde, 2-5 enjeksiyon olarak yapılır (Şekil 1'de 12 yaşlarında humerus ve femur lokalizasyonlu iki ayrı BKK tanılı hastanın steroid enjeksiyonu öncesi ve ikişer enjeksiyondan bir yıl sonraki radyografileri görülmektedir). Radyolojik iyileşme, ilk enjeksiyondan 5-6 ay sonra ortaya çıkabilir. Oppenheim ve arkadaşları 1984'te, küretaj ve greftleme ile steroid enjeksiyonu yöntemini karşılaştırmış ve bir farklılık göremediklerini bildirmişlerdir. ${ }^{[14]} 1986$ 'da Campanacci ve arkadaşları ve daha sonra 1992'de Myelle ve arkadaşları, steroid enjeksiyonunun küretaj greftlemeye üstün olduğunu bildirmişlerdir. ${ }^{[12,16]}$
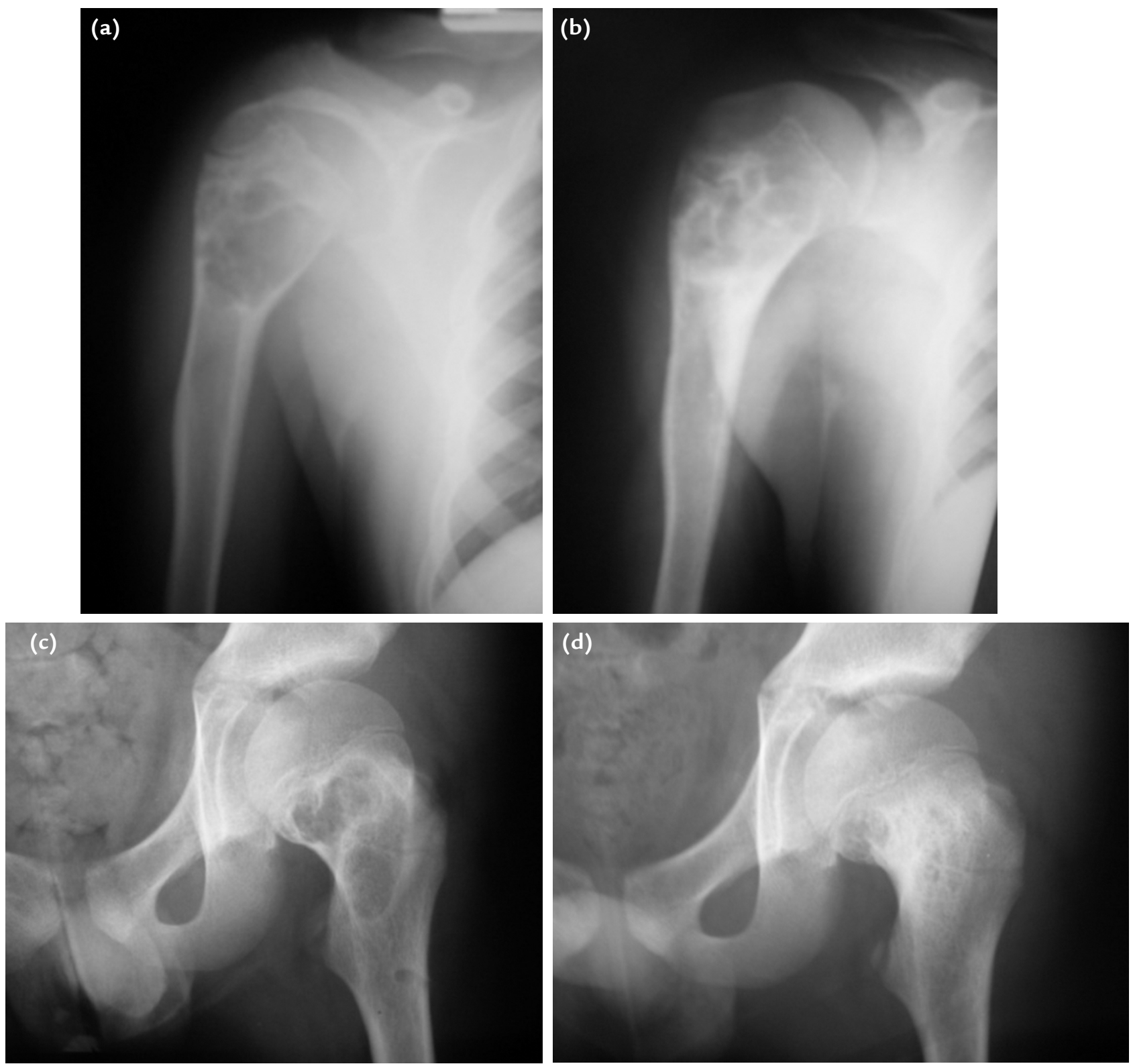

Şekil 1. a-d. Steroid enjeksiyon ile tedavi edilen iki ayrı basit kemik kisti olgusunun grafileri. 
Daha sonra birçok çalışmada bu iki teknik karşılaştırılmış ve birbirine üstünlüğü gösterilememiştir. ${ }^{[17-19]}$ Gennari ve arkadaşları 1995 'te, osteosentez tekniğini yukardaki iki teknikle karşılaştırmış fakat sonuçlarda bir farklılık görememişlerdir. ${ }^{[20]}$ Daha sonra Bensahel ve arkadaşları, rezeksiyon ve myoplasti tekniğinin steroid enjeksiyonuna üstün olduğunu iddia etmişlerdir. [21] Daha sonra Tsuchiya ve arkadaşları 2002'de, multipl drilleme, kanüllü vida uygulaması, steroid enjeksiyonu ve myoplasti yöntemlerini karşılaştırmış ve anlamlı bir fark görmemişlerdir. ${ }^{[22]}$ Chang ve arkadaşları aynı yıl, Cho ve arkadaşları ise 2007'de, steroid ile otolog kemik iliği enjeksiyonlarının aynı sonuçları verdiğini belirtmişlerdir. ${ }^{[23,24]}$ Chuo ve arkadaşları 2003'te, internal fiksasyon ile kanüllü vida yöntemlerini karşılaştırmış ve aynı sonuçları görmüşlerdir. ${ }^{[25]}$ Sancthis 2006 'da, elastik intramedüller çivi ile kistin devamlı drenajının sağlanabildiğini vurgulamış ve Capanna radyolojik kriterlerine göre $\% 66$ tam, \%34 kısmi iyileşme bildirmiştir. ${ }^{[26]}$ Mylle ve arkadaşları, küretaj ve greftleme tedavisine steroid ekleyerek başarıyı arttırmayı denemişler fakat sadece steroid enjeksiyonuna üstün olmadığını bildirmişlerdir. ${ }^{[12]}$ Donaldson ve arkadaşları 1966-2010 yılları arasında Level I-III çalışmaları inceleyerek, kanıta dayalı bir BKK tedavi makalesi yazmışlardır. ${ }^{[27]} \mathrm{Bu}$ çalışmanın özeti Tablo 1'de verilmiştir. Çok değişik yöntemlerle farklı sonuçlar alındığı görülmektedir. Ancak tablo incelendiğinde, olguların çoğunun küretaj ve greftleme ile steroid enjeksiyonu yöntemleri uygulanarak tedavi edildiği görülmektedir. BKK tedavisinde radyoloji dört Grade'li bir sistem ile değerlendirilir: Grade 1'de litik kist görüntüsü vardır; Grade 2'de kist görüntüsü vardır ama multiloküler ve opak görünümdedir; Grade 3'te sklerosis ama kısmen görülebilen kist vardır; Grade 4'te ise tam obliterasyon ve iyileşme görülmektedir. Başka bir değerlendirmede ise, Chang ve arkadaşları Neer klasifikasyonunu modifiye etmişlerdir. Tam iyileşmede; kist yeni kemikle doludur ama 1 $\mathrm{cm}$ altında radyolusen alan olabilir. Defektle iyileşmede; kortekste \%50'nin altında hasar, kırığı önleyecek kadar sağlam kemik ve statik radyolusen saha vardır. Persistan kistte; kortekste \%50'nin üzerinde incelme vardır ama kist büyümüyordur. Rekürren kistte ise; rezidüel saha büyüyor ve eski haline dönüyordur. [24]

\section{Sonuç}

BKK ilk olarak Virchow tarafından tanımlandığından beri değişik tedaviler ortaya atılmıştır. Buna rağmen bugüne kadar hiçbir tedavide uzlaşıya varılamamıştır. Patolojik kırık sonrası kırık iyileşmesi beklenir ve gerekirse daha sonra tedaviye başlanır. Literatürde en çok uygulanan iki yöntemin küretaj ve greftleme ile steroid enjeksiyonu olduğu görülmektedir. Steroid enjeksiyonunda, küretaj ve greftlemeye göre açık cerrahi morbiditesinde azalma olmakla birlikte 2-5 enjeksiyon gerekliliği, hastanın daha fazla genel anestezi almasını gerektirmektedir. Tedavi yöntemine karar verilirken aile çok iyi bilgilendirilmelidir. Epifize komşu aktif lezyonlarda epifize zarar vermemek amacıyla steroid enjeksiyonu tercih edilebilir ve multipl enjeksiyon ihtimali için aile uyarılmalıdır.

Tablo 1. BKK'de değişik tedavi yöntemleri ve başarı oranlarının karşılaştırılması

\begin{tabular}{|c|c|c|c|}
\hline Tedavi yöntemi & Vaka no. & Başarı \% & Literatür \\
\hline Steroid enj & 563 & $15-100$ & {$[20,22,23,27-29]$} \\
\hline Kemik iliği enj. & 81 & $23-92$ & {$[22,23]$} \\
\hline Küretaj ve greftleme & 447 & $36-85$ & {$[11,15,16,18,27,28-30]$} \\
\hline Kanüllü vida & 35 & $46-100$ & {$[24,28]$} \\
\hline Steroid enj.+ DBM + Kemik iliği & 34 & $29-50$ & [29] \\
\hline Küretaj ve greft. + Açık redüksiyon ve int. tespit & 4 & 75 & [24] \\
\hline Küretaj + Multipl drilleme + Titanyum kanüllü vida & 15 & 80 & [21] \\
\hline Küretaj + Multipl drilleme + Hidroksiapatit çivi & 11 & 100 & [21] \\
\hline Rezeksiyon ve myoplasti & 50 & 72 & [20] \\
\hline Küretaj + Greftleme + Osteosentez & 10 & 100 & [19] \\
\hline Kist rüptürü + Osteosentez & 60 & 60 & [19] \\
\hline Ortopedik tedavi & 70 & $4-100$ & {$[2,17,19]$} \\
\hline Karışık cerrahi & 15 & 87 & [17] \\
\hline
\end{tabular}




\section{ANEVRIZMAL KEMIK KISTi}

Anevrizmal kemik kisti (AKK), kemiği ekspanse, hatta bazen tamamen harap eden kistik, vasküler tümör benzeri bir oluşumdur. Klinik karakteri, sessiz bir lezyondan bir sarkomu taklit eden agresif davranışa kadar değişik bir spektrum gösterir. Illk tanımlamayı Jaffe ve Lichtenstein 1942'de basit kemik kisti ile ilgili makalelerinde yapmışlardır. Radyolojik olarak sabun köpüğü görünümünde olduğunu, kemiği ekpanse ettiğini ve ameliyatta basit kemik kistinin aksine pıhtılaşmamış kan içerdiğini belirtmişlerdir. ${ }^{[3]}$ AKK hayatın ikinci dekatında sık görülen, 100.000 kişilik popülasyonda 0,14 rastlanan, patogenezi hemodinamik bozukluklarla tanımlanmaya çalışılan ve kemiğin psödotümörleri sınıflamasında yer alan bir lezyondur. USP6 ve $\mathrm{CDH} 11$ onkojenleri primer AKK neoplastik hücrelerinde tanımlanır ve sekonder AKK'lerin primerlerden ayırımında kullanılır. ${ }^{[32]}$ Uzun kemiklerde metafize yerleşir. Hiçbir zaman epifizden köken almaz. Erişkin hastalarda lezyon epifizi geçebilir. Kemikte yerleşimi kemiğin yüzeyine, genellikle periostun altına yerleşir. Buradan dışa doğru ekspanse olur ve alttaki kortikal kemiği erode eder. Vertebrada posterior ark ve corpusu birlikte tutar. Pelvis, klavikula ve el ayak kemiklerini de tutabilir. Lezyon süperfisiyel olduğu için şişlik ve ağrı ana semptomlardır. Semptomların ortaya çıkmasında olguların üçte birinde travma sorumludur. ${ }^{[33]}$ Çok nadiren patolojik kırık görülür. Vertebral lokalizasyonlarda myeloradikular kompresyon gelişebilir. Agresif lezyonlarda hızlı progresyon gösterebilir.

\section{Radyoloji}

Lezyon başlangıçta eksentrik yerleşimi nedeniyle kolay tanınır, ancak hastalık ilerleyip kemiğin korteks ve medullasını erode edince santral yerleşimli bir tümörü taklit edebilir. Olguların yarısında radyografik olarak subperiosteal yerleşim görülür. Subperiosteal yerleşimde, lezyonun başlangıç döneminde periost balon şeklinde kalkar. illk dönemde periost görünmeyebilir ve alttaki korteksi de yediği için malignensilerle karışabilir. Daha ileri fazda lezyon matüre olur ve periost kabuğu kalınlaşarak, belirginleşir. Bu görüntü alışkın olmayan bir göz için kemik içinden kaynaklanan korteksi inceltip ekspanse eden bir lezyon izlenimi verebilir. Santral yerleşimlilerde ise; başlangıçta osteolitik bir alandır, eksentriktir ve fibula, radius, ulna, el ve ayak tübüler kemiklerinde kemiğin tüm çapını kapsayan bir görüntü verebilir. Bilgisayarlı tomografi (BT) ve manyetik rezonansta (MR), kist içinde SIVI - SIVI seviyesi görüntüsü vardır ve bu AKK için spesifik bir görüntüdür. [34] Kemik sintigrafisinde; özellikle periferinde artmış tutulum ve merkezde azalmış tutulum vardır. Benzeri şekilde, anjiyografilerde kenarlarda orta derecede vaskülarite, merkezde relatif avaskülarite görülür.

\section{Makroskopik görüntü}

AKK cerrahi olarak açıldığında; pulsatil olmayan, kontrol edilebilir ama ciddi bir kanama ile karşılaşırız. Ameliyat sırasında, tümör dokusu çıkartıldıkça yeniden kanama olur. Tümörün kesit yüzeyi tipiktir. Sıvı, kan emdirilmiş ve üzerinde yer yer kan pıhtıları olan bir spongioz doku gibidir.

\section{Mikroskopik görünüm}

AKK'nin duvar ve hematik kavitenin septaları; kapillerlerden zengin histiofibroblastik doku ve multinukleik dev hücreler olarak görülür. Merkezdeki dokuda, kanla dolu kavernöz sinüsler, benign spindle hücreleri ve yeni kemik trabekülleri vardır.

\section{Patogenez}

AKK bir neoplazm olmadığı için, histolojik yapısı hemoraji ile birlikte olan reaktif ve tamir dokusudur. Giant cell, fibröz displazi, kondroblastom, osteoblastom gibi lezyonların bazı alanlarında mikroskopik olarak AKK'ye benzeyen görüntü vardır. Bu noktada AKK'nin başka bir lezyona sekonder mi geliştiği yoksa lezyonun kistik hemorajik yapısal değiş̧ikleri mi olduğu tartışmalıdır. AKK, lokal vasküler hemodinamik bir değişiklikle, muhtemelen kemik içi dolaşımda bir bozulmayla ve lokal hemoraji ile başlar. ${ }^{[3]}$ Bunun sonucunda bir tamir dokusu ile birlikte osteolitik bir görüntü oluşur ve hemoraji artarak kısır döngü ile kist giderek büyüyebilir. Başka bir makalede, Dabezies ve arkadaşları, çocuklarda kırık sonrası AKK kisti görüldügüünü ve buna dayanarak travmanın etiyolojide rol oynayabileceğini iddia etmişlerdir. ${ }^{[33]}$ Fakat bazı olgularda bu oluşumun giderek yavaşladığı ve kistin matür hale geldiği, hatta spontan olarak iyileşebildiği bildirilmektedir. Bunu destekleyen bulgular; AKK'nin içindeki dokunun damar dokusu olmaması ve arteriyografilerde belirgin bir afferent veya efferent damar gösterilememesidir. ${ }^{[12]}$

\section{Tanı}

Direkt grafide subperiosteal balonlaşma genellikle AKK'den şüphelenmek için yeterlidir. Merkezi olanlarda BKK ile karışabilir. Ancak BKK'de çok büyük oranda humerus ve femur proksimal yerleşimi vardır. Ayrıca BKK her zaman metafizin merkezinde epifize komşu bölgede görülür. Kemiğin dev hücreli tümörü ise çok nadiren epifiz açıkken görülür. MR'de çift dansite sıvı seviyesi, septasyonlar ile birlikte T1'de düşük ve T2'de yüksek sinyal olduğu zaman AKK düşünülmelidir. ${ }^{[35]}$ AKK'nin aggresif destrüktif formunda, korteks tamamen lizise giderek, sınırları belirsiz litik bir malign tümör görüntüsü ile klinik ve radyolojik yanılmaya yol açabilir. Histopatolojik olarak giant cell, brown 
tümör, fibröz displazi, kondroblastom, osteoblastom gibi tümörlerin bazı alanlarında AKK'ye benzer kistik hemorajik alanlar tanıda yanılgıya yol açabilir. Bazı yayınlarda bu lezyonlara sekonder AKK gelişebildiği bildirilmiştir. ${ }^{[36]}$

\section{Hastalı̆ıın seyri}

Hastalığın seyri değişiklik gösterir. Bazen yavaş büyürken, genelde hızlı ve progresif bir tablo ile karşılaşırız ve tümör dev boyutlara ulaşabilir. Bu hızı büyüme yüzünden tanıda semptomların süresi genellikle altı aydan daha kısa sürelidir. Fakat bazı olgularda, tedavi edilmese bile kistin büyümesi durur ve yavaş bir ossifikasyona giderek 2-3 yıl içinde iyileşebilir. AKK'nin bu matürasyonu, radyasyon veya selektif arteriyel embolizasyonla indüklenebilir.

\section{Tedavi}

Marjinal eksizyonda \%20 rekürrens verilmiştir. ${ }^{[34,37]}$ Tedavide ekstraperiosteal eksizyon ve küretajla birlikte fenol, sıvı nitrojen ve kemik çimentosu gibi lokal adjuvanlar ve ardından grefonaj yapılır. ${ }^{[38,39]}$ Küretaj ve greftlemeye örnek bir femur proksimal AKK olgusunun ameliyat öncesi ve sonrası radyografileri Şekil 2-5'te gösterilmiştir. Fibula, kosta, metakarp ve metatarslarda segmental rezeksiyon yapılabilir. Kan

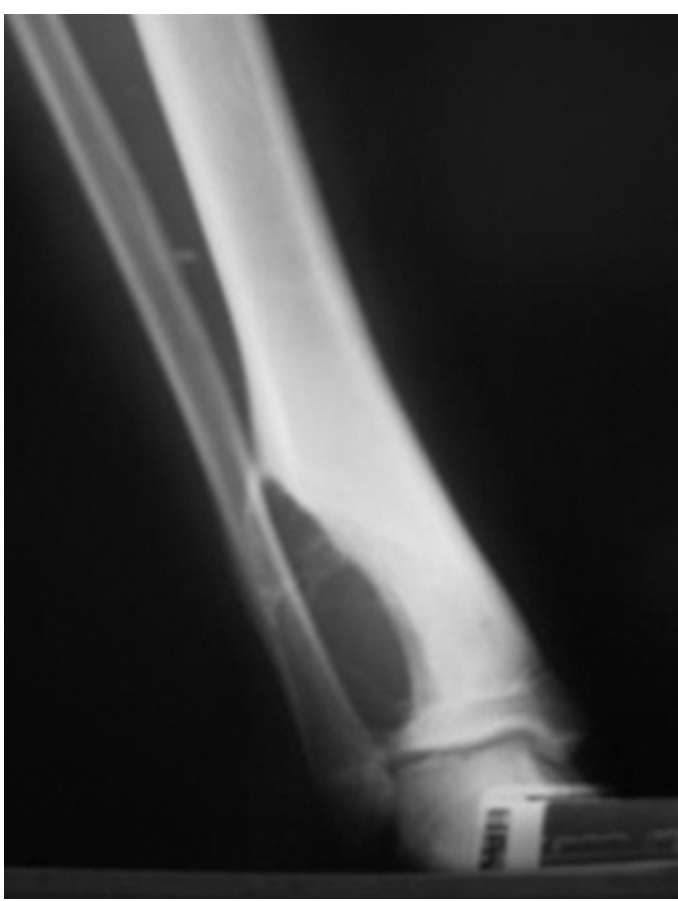

Şekil 2. Tibia distal AKK radyografisi. Subperiosteal yerleşimli ve erken dönemde perifer kortikalize olamamış durumda.

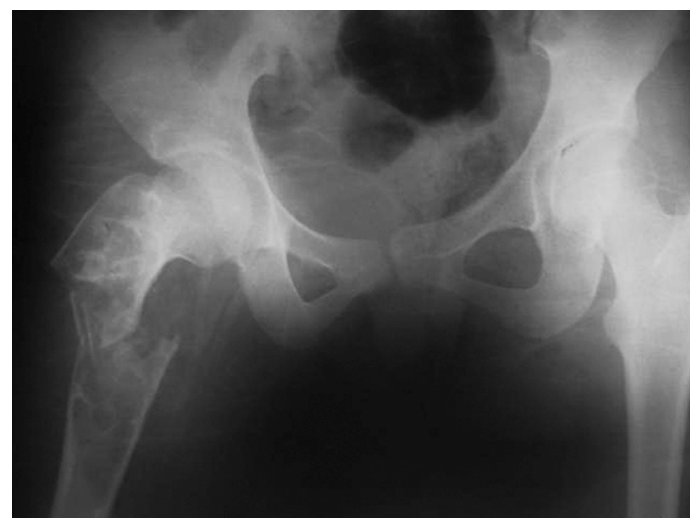

Şekil 4. 18 yaşında kadın hastanın femur proksimal AKK radyografisi.

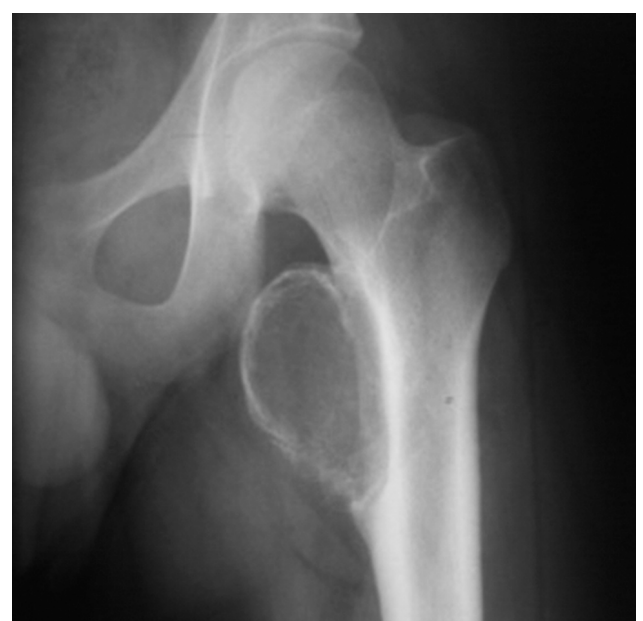

Şekil 3. Femur proksimal AKK radyografisi. Subperiosteal yerleşimli ve perifer kortikalize olmuş durumda.

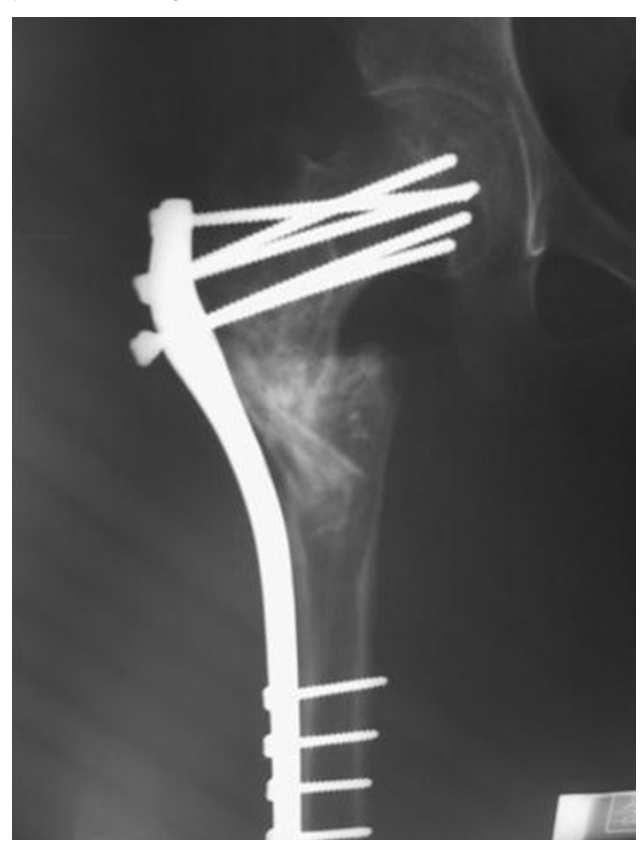

Şekil 5. Şekil 3'teki hasta küretaj ve greftleme sonrası postoperatif 9. aydaki radyografisi. Hasta desteksiz yürüyebilir durumda. 
kaybını önlemek için turnike veya ana arterin geçici olarak kapatılması (örneğin pelvik AKK'lerde iliak arter) gerekir. Vertebra, pelvis ve proksimal femurda selektif arteriyel embolizasyon uygulanabilir. Bazen embolizasyon kistte ameliyatsız iyileşmeyi sağlar. Riskli bölge veya dev AKK'lerde bu yöntemi uygulamak gerekebilir. Ayrıca radyoterapi ile AKK dokusu matür hale gelir. Ancak radyoterapi, radyasyona sekonder sarkom gelişme riskine karşılık, ameliyatı mümkün olmayan ve embolizasyonun başarısız olduğu olgulara yapılır. Papagelopoulos ve arkadaşları, genellikle agresif seyreden pelvis ve sakrum AKK'lerinde adjuvan radyoterapi gerekebildiğini ve nükslerin \%15'te tutulabileceğini bildirmişlerdir. ${ }^{[40]}$ Gibbs ve arkadaşları, küretaj ve greftlemeye ek olarak "burr" drill ile korteksi temizlemişlerdir; nüks oranını \%10 olarak bildirmişler ve bu nüks için en büyük risk faktörünü epifizi açık olan hastalar (küçük yaş) olarak bildirmişlerdir. ${ }^{[41]}$ Kist içine Ethibloc enjekte eden George ve arkadaşları, \%58 tam, \%35,5 kısmi iyileşme ve $\% 6,5$ rekürrens ile başarılı bir uzun takip serisi yayımlamışlardır. ${ }^{[42]}$ Ayrıca küretaj ve greftlemeye ek olarak argon ışını koagülasyonunu adjuvan olarak kullanmışlar ve hiç rekürrens olmadığını bildirmişlerdir. ${ }^{[43]}$

\section{Prognoz}

AKK'lerin tamamına yakını küretaj ve greftleme yöntemi uygulanan tedavi sonrasında iyileşir (bazen embolizasyon gerekebilir). Ancak, \%10-15 oranında nüks bildirilmiştir. Radyoterapi, dev boyutlarda olsa bile AKK'yi kurutur. Vertebra tutulumunda medüller basıya bağıı nörolojik değişiklikler cerrahi dekompresyon sonrasında hızlı bir iyileşme gösterir. Nadiren de olsa metastaz yapabileceği gösterilmiştir. ${ }^{[44]}$

\section{KAYNAKLAR}

1. Scaglietti O, Marchetti PG, Bartollozi P. The effects of metilprednisolone acetate in the treatment of bone cysts. Results of three years follow-up. J Bone Joint Surg $\mathrm{Br}$ 1979;61-B(2):200-4.

2. Mendenhall WM, Zlotecki RA, Gibbs CP, Reith JD, Scarborough MT, Mendenhall NP. Aneurysmal bone cyst. Am J Clin Oncol 2006;29(3):311-15.

3. Jaffe HL, Lichtenstein L. Solitary unicameral bone cyts: with emphasis on the roentgen picture, the pathologic appearance and the pathogenesis. Arch Surg 1942;44(6):1004-25. CrossRef

4. Hammoud S, Weber K, Mc Carthy EF. Unicameral bone cysts of the pelvis: a study of 16 cases. lowa Orthop J 2005;25:69-74.

5. Moreau G, Letts M. Unicameral bone cyst of the calcaneus in children. J Pediatr Orthop 1994;14(1):101-4.

6. Polat O, Sağlik Y, Adıgüzel HE, Arikan M, Yildiz HY. Our experience on calcaneal bone cysts. 36 cysts in 33 patients. Arch Orthop Trauma Surg 2009;129(11):1489-94. CrossRef
7. Hagmann S, Eichorn F, Moradi B, Gotterbarm T, Dreher T, Lehner B, Zeifang F. Mid- and long-term results of surgical therapy in unicameral bone cysts. BMC Muscloskelet Disord 2011;12:281. CrossRef

8. Neer CS, Francis KC, Johnston AD, Kiernan HA Jr. Current consepts on the treatment of solitary unicameral bone cyst. Clin Orthop Relat Res 1973;(97):40-51.

9. Komiya S, Minamitani K, Sasaguri Y, Hashimoto S, Morimatsu M, Inoue A. Simple bone cyst: treatment by trepanation and studies on bone resorbtive factors in cyts fluid with a theory of its pathogenesis. Clin Orthop Relat Res 1993;(287):204-11.

10. Dietrich JW, Goodson JM, Raisz LG. Stimulation of bone resorption by various prostaglandins in organ culture. Prostaglandins 1975;10(2):231-40.

11. Komiya S, Kawabata R, Zenmyo M, Hashimoto S, Inoue A. Increased concentrations of nitrate and nitrite in the cyst fluid suggesting increased nitric oxide synthesis in simple bone cyst. J Ortop Res 2000;18(2):281-8.

12. Campanacci M, Capanna R, Picci P. Unicameral and aneurysmal bone cysts. Clin Orthop Relat Res1986;(204):25-36.

13. Yu CL, D'Astous J, Finnegan M. Simple bone cyst: the effects of methylprednisolone on synovial cells in culture. Clin Ortop Relat Res 1991;(262):34-41.

14. Capanna R, Dal Monte A, Gitelis S, Campanacci M. The natural history of unicameral bone cyst after steroid injection. Clin Orthop Relat Res 1982;(166):204-11.

15. Mylle J, Burssens A, Fabry G. Simple bone cysts: a review of 59 cases with special reference to their treatment. Arch Orthop Trauma Surg 1992;111(6):297-300.

16. Oppenheim $W L$, Galleno $H$. Ooperative treatment versus steroid injection in the management of unicameral bone cysts. J Pediatr Orthop 1984;4(1):1-7.

17. Farber JM, Stanton RP. Treatment options in unicameral bone cysts. Orthopedics 1990;13(1):25-32.

18. Bovill DF, Skinner HB. Unicameral bone cysts. A comparison of treatment options. Orthop Rev 1989;18(4):420-7.

19. Pentimalli G, Tudisco C, Scola E, Farsetti P, Ippolito E. Unicameral bone cysts - comparison between surgical and steroid injection treatment. Arch Orthop Trauma Surg 1987;106(4):251-6.

20. Gennari JM, Merrot TH, Piclet/Legre B, Bergoin M. The choise of treatment for simple bone cysts of the upper third of the femur in children. Eur J Pediatr Surg 1996;6(2):95-9.

21. Bensahel $H$, Jehanno P, Desgrippes $Y$, Pennecot GF. Solitary bone cyst: controversies and treatment. J Pediatr Orthop B 1998;7(4):257-61.

22. Cho HS, Oh JH, Kim HS, Kang HG, Lee SH. Unicameral bone cysts: a comparison of injection of steroid and grafting with autologous bone marrow. J Bone Joint Surg $\mathrm{Br}$ 2007;89(2):222-6.

23. Chang $\mathrm{CH}$, Stanton RP, Glutting J. Unicameral bone cysts treated by injection of bone marrow or methylprednisolone. J Bone Joint Surg Br 2002;84(3):407-12.

24. Tsuchiya H, Abdel-Wanis ME, Uehara K, Tomita K, Takagi $Y$, Yasutake $\mathrm{H}$. Cannulation of simple bone cysts. J Bone Joint Surg Br 2002;84(2):245-8.

25. Chuo CY, Fu YC, Chien SH, Lin GT, Wang GJ. Management strategy for unicameral bone cyst. Kaohsiung J Med Sci 2003;19(6):289-95.

26. Sanctis N, Andreacchio A. Elastic stable intramedullary nailing is the best treatment of unicameral bone cysts of the long bones in children?: Prospective long-term study. J Pediatr Orthop 2006;26(4):520-5. 
27. Donaldson S, Chundamala J, Yandow S, Wright JG. Treatment for unicameral bone cysts in long bones: an evidence based review. Orthop Rev (Pavia) 2010;2(1):e13. CrossRef

28. Wright JG, Yando S, Donaldson S, Marley L; Simple Bone Cyst Trial Group. A randomised clincal trial comparing intralesional bone marrow and steroid injections for simple bone cysts. J Bone Joint Surg Am 2008;90(4):722-30. doi: 10.2106/JBJS.G.00620

29. Brecelj J, Suhodolcan L. Continuous decompresion of unicameral bone cyst with cannulated screws: a comparative study. J Pediatr Orthop B 2007;16(5):367-72.

30. Sung AD, Anderson ME, Zurakowski D, Hornicek FJ, Gebhardt MC. Unicameral bone cyst: a retrospective study of three surgical treatments. Clin Orthop Relat Res 2008;466(10):2519-26. CrossRef

31. Neer CS 2nd, Francis KC, Marcove RC, Terz J, Carbonara PN. Treatment of unicameral bone cyst. A follow-up study of one hundred seventy-five cases. J Bone Joint Surg Am 1966;48(4):731-45.

32. Oliveria A, Perez-Atayde AR, Inwards CY, Medeiros F, Derr V, Hsi BL, Gebhardt MC, Rosenberg AE, Fletcher JA. USP6 and $\mathrm{CDH} 11$ oncogenes identify the neoplastic cell in primary aneurysmal bone cysts and are absent in so-called secondary aneurysmal bone cysts. Am J Pathol 2004;165(5):1773-80.

33. Dabezies EJ, D’Ambriosia RD, Chuinard RG, Ferguson AB Jr. Aneurysmal bone cyst after fracture. A report of three cases. J Bone Joint Surg Am 1982;64(4):617-21.

34. Brastianos P, Gokaslan Z, McCarthy EF. Aneurysmal bone cysts of the sacrum: a report of ten cases and review of the literature. lowa Orthop J 2009;29:74-8.

35. Sullivan RJ, Meyer JS, Dormans JP, Davidson RS. Diagnosing aneurysmal and unicameral bone cysts with magnetic resonance imaging. Clin Orthop Relat Res 1999;(366):186-90.
36. Snieders MN, van Kemenade FJ, van Royen BJ. Monostatik fibrous dysplasia of a lumbar vertebral body with seconder aneurysmal bone cyst formation: a case report. J Med Case Rep 2009;3:7227. CrossRef

37. Marcove RC, Sheth DS, Takemoto S, Healey JS. The treatment of aneurysmal bone cyst. Clin Orthop Relat Res 1995;(311):157-63.

38. Capanna R, Sudanese A, Baldini N, Campanacci M. Phenol as an adjuvant in the control of local recurrence of benign neoplasms of bone treated by curettage. Ital J Orthop Traumatol 1985;11(3):381-8.

39. Peeters SP, Van der Geest IC, Rooy JW, Veth RP, Schreuder HW. Aneurysmal bone cyst: the role of cryosurgery as local adjuvant treatment. J Surg Oncol 2009;100(8):719-24. CrossRef

40. Papagelopoulos PJ, Choudhury SN, Frassica FJ, Bond JR, Unni KK, Sim FH. Treatment of aneurysmal bone cyst of the pelvis and sacrum. J Bone Joint Surg Am 2001;83-A(11):1674-81.

41. Gibbs CP Jr, Hefele MC, Peabody TD, Montag AG, Aithal V, Simon MA. Aneurysmal bone cyst of the extremities. Factors related to local recurrence after curettage with high-speed burr. J Bone Joint Surg Am 1999;81(12):1671-8.

42. George HL, Unnikrishnan PN, Gak NK, Sampath JS, Bass A, Bruce CE. Long-term follow-up Ethibloc injection in aneurysmal bone cysts. J Pediatr Orthop B 2009;18(6):37580. CrossRef

43. Cummings JE, Smith RA, Heck RKJr. Argon beam coagulation as adjuvant treatment after curettage of aneurysmal bone cysts: a preliminary study. Clin Orthop Relat Res 2010;468(1):231-7. CrossRef

44. van de Luijtgaarden AC, Veth RP, Slootweg PJ, Wijers-Koster PM, Schultze Kool LJ, Bovee JV, van der GraafWT. Metastatic potential of an aneurysmal bone cyst. Virchows Arch 2009;455(5):455-9. CrossRef 